\title{
The Effect of Life Skills Training on Controlling the Aggression of Drug Addicts under Treatment
}

\author{
Ali Navidian ${ }^{1}$, Elahe Moshtaghi², Nasrin Rezaee ${ }^{3}$ \\ ${ }^{1}$ Department of Nursing, Pregnancy Health Research Center, Zahedan University of Medical Sciences, Zahedan, Iran. \\ ${ }^{2}$ Department of Nursing, Faculty of Nursing and Midwifery, Medical Science, branch of Islamic Azad University, \\ Zahedan, Iran. ${ }^{3}$ Department of Nursing, Community Nursing Research Center, Zahedan University of Medical Sciences, \\ Zahedan, Iran.
}

\section{ABSTRACT}

\section{BACKGROUND}

Anger control is one of the methods that can help drug addicts under treatment to have a good interaction with healthy people. The aim of this study was to determine the effect of life skills training on the anger control of the addicts attending the psychiatric center in Iran.

\section{METHODS}

In this quasi-experimental study, 70 drug addicts who were attending the psychiatric center were selected and assigned into two groups. The data was collected from 1 Jan 2016 to 30 May 2017. Convenience sampling was performed. The data collection tool was Aggression Questionnaire. Samples in the intervention group received LST in 4 sessions per week. After 8 weeks from the end of the intervention, the level of anger control was evaluated in both groups.

\section{RESULTS}

The Mean $\pm S D$ of anger control before training in the intervention and control groups were $86.05 \pm 19.00$ and $80.57 \pm 18$. 03, respectively. After intervention, this figure was reduced to $65.22 \pm 21.85$ in the intervention group and in the control group, it increased to $81.62 \pm 16.84$.

\section{CONCLUSIONS}

LST significantly increased the anger control ability and decreased aggressive behaviours in the intervention group. The LST reduced the aggressive behaviours of individuals who were overcoming a drug addiction and also as controlling anger is one of the methods that prevent addicts from retaking drug.
Corresponding Author:

Nasrin Rezaee,

Community Nursing Research Center,

Zahedan University of Medical Sciences, Zahedan, Iran.

E-mail: nasrin_rezaee2005@yahoo.com

DOI: $10.14260 / j e m d s / 2019 / 830$

Financial or Other Competing Interests: None.

How to Cite This Article:

Navidian A, Moshtaghi E, Razaee N. The effect of life skills training on controlling the aggression of drug addicts under treatment. J. Evolution Med. Dent. Sci. 2019;8(51):3830-3835, 10.14260/jemds/2019/830

Submission 10-08-2019,

Peer Review 07-12-2019,

Acceptance 14-12-2019,

Published 23-12-2019.

\section{KEY WORDS}

Life, Skills, Anger, Addiction 


\section{BACKGROUND}

Addiction and drug abuse are among the most significant psychosocial problems that can negatively affect the life of individuals and socio-cultural life of a country. Addiction is a psycho-physiological phenomenon and many variables influence its onset, continuation, and treatment. Addicted person is rendered unable to control the addiction due to the physical and mental dependency associated with the addition.[1] Today, most people perceive drug abuse as a chronic, recurring, and multiple-dimensional disease that its treatment is a major challenge. The findings have shown that many abusers have resumed drug use within 90 days after detoxification. ${ }^{[2]}$ In addition, there is a repetitive pattern of use in addiction often leading to intolerance of deprivation and compulsory behaviour for substance use.[3] On the other hand, factors such as low self-esteem, lack of problem solving skills, lack of effective thinking during crisis, bad temper, psychosocial problems, and lack of human emotions in the social environment play important role in the tendency of people towards drug abuse. ${ }^{[4]}$

One of the unfavourable outcomes many individuals face during and after drug detoxification is the issue of anger and aggression. Findings suggest that, the person's inability to express the emotions and feeling is closely connected to anger that can act as one of the main motives towards addiction recurrence.[5] Many studies have shown the relationship between aggressive behaviour and drug use.[1,6] When addicts try to solve their addiction problem, those who are more sensitive, feel more anger and frustration, so they tend to abuse drugs to cope with such excitement. [6] As the findings suggest, there is a relationship between domestic violence and drug abuse in married men.[7] Moreover, other findings showed that addicted people (14.6\%) had less ability to communicate effectively and control aggression compared to non-addicts (28.8\%).[8] In addition, addicts use various types of violence, harassment and harm to solve their interpersonal problems. ${ }^{[9]}$

Many studies have shown that drug abusers have difficulty in regulating their emotions, or the state of their negative emotion accelerates the drug use.[9,10] In general, those who cannot control their compulsive behaviours are likely to become a permanent consumer of drugs.[11] Mutually, intolerance of failure results in aggressive behaviours and acting in an irresponsible manner, resulting in the destruction of interpersonal relationships and the use of addictive drugs. [12] A review of the literature showed that some interventions to control anger in detainees led to the control of anger in terms of verbal and physical aggression and belligerence.[12,13] Studies show that appropriate therapeutic interventions can significantly reduce the risk of drug and substance abuse after the intervention,[14,15] but most detoxification interventions only focus on the drug treatment. However, some studies have shown that nonpharmacological treatments have a deterrent role in recurrence or, in other words, re-use of addictive substances. [16-18] Therefore, in addiction to drug treatments, the use of non-pharmacological treatments is also essential. One of the non-pharmacological interventions is psychological intervention. Treatments that have been made so far include cognitive behavioural therapies, stress management training, encouragement training and motivational intervention.[1,16,19-20] Various studies have recently been done on LST. Studies conducted have focused on aspects of drug-abuse treatment programs, such as marital satisfaction, quality of life, and stress reduction, which have shown the effectiveness of LST on these factors.[4,21]

LST is a comprehensive program that is designed to teach a wide range of personal and social skills to people and has a high potential for preventing social problems and harms. Some studies have shown that lack of life skills is connected with drug abuse.[21] LST can improve the quality of life of patients who are trying to stop their addiction, and helps people to use effective techniques to deal with stress and emotional excitement.[22,23] There is a program of life skills for the purpose of promoting mental health and preventing social harms, the stress of this program is on the development of social skills.[24]

Taking into account the cultural factors, some misguided beliefs and special geographical conditions such as neighbouring major opium producing countries (Afghanistan and Pakistan); Iran has the right conditions for addiction epidemic. The importance of considering the issue of drug abuse in Iran is due to its high prevalence and spread among people. World Health Organization's (2008) annual report states that, there are about 220 million opium addicts in the world, and according to predictions, this number will reach to 1.36 billion by 2025 which is equal to $16 \%$ of the world's population, and unfortunately, the highest prevalence of addiction is in Iran (2.8 percent) [25].

However, evidence indicates that violence is a predictor of addiction, and aggression can predict the potential for addiction.[22] Thus, this study aimed to determine the effect of LST on the control of anger among drug addicts attending the psychiatric center of Zahedan.

\section{METHODS}

This is a quasi-experimental study with two groups of control and intervention. Sampling was convenience. The study population was selected from patients who had been referred to Psychiatric Center of Zahedan, Iran. This study was conducted from Jan 2016 to May 2017. Definitive diagnosis of drug addiction, lack of mental illness, non-communicable psychiatric disorder, appropriate physical status (For the training participation), only male samples and patients aged between 20 and 40 years were the inclusion criteria, and not attending more than one treatment session was the exclusion criterion in this study. Because of the possibility of transferring data between the intervention and control groups, the control group was sampled (Convenience) by completing pre-test and post- test questionnaires. Then, the intervention group sampling (convenience) was done so that pre-test questionnaires were completed. Then, four sessions of intervention (8-10) were performed. Four weeks after the intervention, post-test questionnaires were completed.

Sample size was determined based on the mean and standard deviation in the similar study, ${ }^{[24]}$ considering $95 \%$ confidence interval, and power to test $95 \%$. Moreover, based on the following sample size formula, 15 subjects were allocated in each group. However, according to the number of variables studied, the probability of drop out, and to increase the reliability of the study, 45 subjects were considered for 
each group. However, we faced sample loss as some of the participants did not complete the questionnaires and access to some samples in the post-test phase was not possible. At the end, 35 subjects in the intervention group and 35 in the control group were analysed.

$$
\begin{aligned}
& \mathrm{n}=\frac{\left(Z_{1-\frac{\alpha}{2}}+Z_{1-\beta}\right)^{2}\left({S_{1}}^{2}+S_{2}{ }^{2}\right)}{\left(\bar{X}_{1}-\bar{X}_{2}\right)^{2}}=15 \\
& Z_{1-\frac{\alpha}{2}}=1.96 S_{1}=3.70 \overline{X_{1}}=16.66 \\
& Z_{1-\beta}=1.64 S_{2}=6.50 \overline{X_{2}}=23.83
\end{aligned}
$$

The data collection tools included a demographic information questionnaire and 29-item anger questionnaire (AQ) of Buss and Perry. Demographic characteristics included age, education, occupation, marital status, duration of addiction, type of drug and number of quitting attempts. Anger Questionnaire was developed in 1992 with 29 items. The questionnaire is scored in a 5-option Likert scale from 1 to 5 . In this questionnaire, the score ranges from 29 to 145 . The higher score indicates the higher level of anger. Each item is scored as follow: completely similar to me (5), somewhat similar to me (4), average (3), somewhat different from me (2), and completely different from me (1). Moreover, questions 9 and 16 are scored reversely.[26]

Buss and Perry (1992) have designed these questions based on the review of the literature, then applied factor analysis on the questions and finally a questionnaire containing 29 questions with four dimensions was developed. The reliability of this questionnaire was evaluated by the designers with a test, re-test method. The correlation coefficient of four subscales including physical aggression was 0.80 verbal aggression was 0.76 , anger was 0.72 , and hostility was 0.72.[27] In Iran, the internal consistency of the subscales was calculated to be $0.79-0.84$ and the total score was $0.89 .{ }^{[26]}$ In this study, reliability was also calculated through Cronbach's alpha coefficient and was equal to 0.85 .

To select the samples, first, people who were attending the psychiatric center for drug detoxification and met the inclusion criteria were identified (By reviewing the case). The samples entered the study by giving an oral informed consent. At first, 45 subjects were selected for control group through convenient sampling. Subsequently, 45 others were selected in the same manner and assigned into the intervention group. At the end of the study, 35 subjects were in the control group and 35 in the intervention group due to the sample drop out. After the formation of the groups, the samples were asked to complete the questionnaires and some meetings were organized. Pre-test (Completing demographic and AQ questionnaires) was done by both groups. To control the confounding variables, homogenization was considered in terms of gender and age.

The intervention group received some of the life skills (Self-awareness, interpersonal relationships, emotional management, coping with stress, decision-making, and selfexpression) based on the skills provided by WHO. [28] Four sessions were held every other day (3 days a week) in groups of 4 to 8 people in form of discussion. The duration of each session was 45 to 60 minutes. A psychiatric nurse ran the training program. Eight weeks after the end of the intervention, the questionnaires were completed again by the samples at home or psychiatric hospital clinic (all questionnaires were filled in by the researcher who was not a

\begin{tabular}{|c|c|c|}
\hline Session & Training content & Implementation \\
\hline $\begin{array}{c}\text { First } \\
\text { session }\end{array}$ & $\begin{array}{l}\text { The concept of LST and its } \\
\text { applications } \\
\text { Self-knowledge skill } \\
\text { training }\end{array}$ & $\begin{array}{l}\text { Evaluation of people's problems for having an overall } \\
\text { estimate } \\
\text { Presentation of the program (providing examples, and } \\
\text { questions and answers with clients) } \\
\text { Assignment for the next session (applying learned skills } \\
\text { training) } \\
\end{array}$ \\
\hline $\begin{array}{l}\text { Second } \\
\text { session }\end{array}$ & $\begin{array}{l}\text { Reminder from past } \\
\text { contents } \\
\text { Interpersonal training and } \\
\text { effective communication }\end{array}$ & $\begin{array}{l}\text { The expression of experiences of the clients and the } \\
\text { challenges they face and the type of coping strategy they } \\
\text { have had. } \\
\text { Presentation of the program (providing examples, and } \\
\text { questions and answers with clients) } \\
\text { The assignment for the next session (Search for what has } \\
\text { been used as a dysfunctional method so far). }\end{array}$ \\
\hline $\begin{array}{c}\text { Third } \\
\text { session }\end{array}$ & $\begin{array}{l}\text { Reminder from past } \\
\text { contents } \\
\text { stress coping and } \\
\text { excitementmanagement } \\
\text { training }\end{array}$ & $\begin{array}{l}\text { Questions and Answers and group discussion on stress } \\
\text { coping skills } \\
\text { Expression of experiences about the management of } \\
\text { anger and the challenges already been faced } \\
\text { Homework for the next session (teaching learned LST, and } \\
\text { searching for what has been used as a dysfunctional } \\
\text { method so far) }\end{array}$ \\
\hline $\begin{array}{l}\text { Fourth } \\
\text { Session }\end{array}$ & $\begin{array}{c}\text { Review of previous sessions } \\
\text { training decision skills and } \\
\text { expressions }\end{array}$ & $\begin{array}{l}\text { Questions and Answers and Group Discussions on } \\
\text { DecisionSkills } \\
\text { Expressions of experience about themethodsused in } \\
\text { decision-making and the challenges faced }\end{array}$ \\
\hline
\end{tabular}
member of the research team). The control group that received no intervention and only routine care was done.

Training content was developed according to WHO's LST Program. ${ }^{[24,28]}$ Among the life skills, those with impact On the study variables, including self-awareness, interpersonal relationships, emotional management, coping with stress, and decision-making skills were chosen for training. A summary of the layout of the meeting and content is presented in Table 1.

\section{Data Analysis}

Data was analysed using SPSS software version 20 and the range of changes was determined with the help of descriptive statistics, frequency percentage, and mean and standard deviation. Inferential statistics used to compare the mean scores before and after the intervention included the paired $t$ test, and the mean scores of intervention and control groups were compared using independent t-test, chi-square and Fisher's exact Test. P-value of less than 0.05 was considered significant.

This study was carried out in Zahedan University of Medical Sciences and registered with the ethical code: IR.ZAUMS.REC.1395.248. Ethical considerations included verbal informed consent, ensuring confidentiality of information and freedom to participate or leave the study at any time with any reason.

\section{RESULTS}

The characteristics of the groups are presented in Table 2. This table shows no significant difference between the control and intervention groups in terms of age $(p=0.67)$, the number of quitting attempts $(\mathrm{p}=0.19)$, duration of addiction 
$(\mathrm{p}=0.59)$, education $(\mathrm{p}=0.3)$, occupation $(\mathrm{p}=0.9)$ and marital status $(\mathrm{p}=0.66)$.

The Mean \pm SD of anger control before and after training in the intervention group was $86.05 \pm 19.00$ and $65.22 \pm$ 21.85 , respectively. Independent t-test showed a significant difference in the Mean \pm SD of anger after LST in the intervention group $(\mathrm{p}<0.001)$, (Table 3 ).

\begin{tabular}{|c|c|c|c|c|}
\hline \multicolumn{2}{|c|}{ Variable } & $\begin{array}{c}\text { Control Group } \\
\text { Mean } \pm \text { SD }\end{array}$ & $\begin{array}{c}\text { Intervention Group } \\
\text { Mean } \pm \text { SD }\end{array}$ & $\mathbf{p}$ \\
\hline \multicolumn{2}{|c|}{ Age(Years) } & \pm 8.1634 .42 & $33.62 \pm 7.68$ & ${ }^{*} 0.67$ \\
\hline \multicolumn{2}{|c|}{ The attempts to quit (Times) } & $3.14 \pm 2.46$ & $4.27 \pm 4.27$ & ${ }^{*} 0.19$ \\
\hline \multicolumn{2}{|c|}{ Duration of addiction (Years) } & $9.94 \pm 7.74$ & $8.99 \pm 6.85$ & $* 0.59$ \\
\hline \multirow{5}{*}{ Education } & Grouping & $\mathrm{N}(\%)$ & $\mathrm{N}(\%)$ & \\
\hline & Reading and writing & $9(25.7)$ & $8(22.9)$ & \multirow{4}{*}{$* * 0.3$} \\
\hline & Basic & $10(28.5)$ & $16(45.7)$ & \\
\hline & Diploma & 14(41.1) & $9(25.7)$ & \\
\hline & Higher & $2(5.7)$ & $2(5.7)$ & \\
\hline \multirow{3}{*}{ Occupation } & Unemployed & $22.9(8)$ & $25.7(9)$ & \multirow{3}{*}{$* * 0.9$} \\
\hline & Self-employed & $4.2(19)$ & $51.4(18)$ & \\
\hline & Other businesses & $22.9(8)$ & $22.9(8)$ & \\
\hline \multirow{2}{*}{ Marital status } & Single & $16(45.7)$ & $15(42.8)$ & \multirow{2}{*}{$* 0.66 *$} \\
\hline & Married & $19(54.3)$ & $20(57.2)$ & \\
\hline \multicolumn{5}{|c|}{$\begin{array}{c}\text { Table 2. Comparison of Demographic Characteristics in the Control } \\
\text { and Intervention Groups }\end{array}$} \\
\hline \multicolumn{5}{|c|}{${ }^{*}$ Independent T-Test ${ }^{* *}$ Fisher exact ${ }^{* * *}$ chi-square } \\
\hline
\end{tabular}

\begin{tabular}{|c|c|c|c|c|}
\hline Time & \begin{tabular}{|c|} 
Before \\
Intervention
\end{tabular} & $\begin{array}{c}\text { After } \\
\text { Intervention }\end{array}$ & Changes & $\mathbf{p}$ \\
\hline & Mean \pm SD & Mean \pm SD & Mean \pm SD & \\
\hline Intervention & $86.05 \pm 19.00$ & $65.22 \pm 21.85$ & $-20.82 \pm 23.37$ & $\begin{array}{c}\mathrm{t}=5.27 \\
\mathrm{df}=34 \\
*_{\mathrm{p}}=0.001\end{array}$ \\
\hline Control & $80.57 \pm 18.03$ & $81.62 \pm 16.84$ & $1.05 \pm 5.70$ & $\begin{array}{c}\mathrm{t}=1.09 \\
\mathrm{df}=34 \\
* \mathrm{p}=0.28\end{array}$ \\
\hline$p$-Value** & $\begin{array}{c}\mathrm{t}=1.23 \\
\mathrm{df}=68 \\
* * \mathrm{p}=0.22\end{array}$ & $\begin{array}{c}\mathrm{t}=3.51 \\
\mathrm{df}=68 \\
* * \mathrm{p}=0.001\end{array}$ & $\begin{array}{c}\mathrm{t}=5.38 \\
\mathrm{df}=68 \\
* * \mathrm{P}<0.001\end{array}$ & \\
\hline \multicolumn{5}{|c|}{$\begin{array}{l}\text { Table 3. Comparison of Mean and Standard Deviation of Anger Score } \\
\text { among Addicts before and after LST in the Intervention and } \\
\text { Control Groups }\end{array}$} \\
\hline
\end{tabular}

\section{DISCUSSION}

This study aimed to determine the effect of LST on the control of anger among drug addicts attending the psychiatric center of Zahedan. The findings of this study indicated the impact of LST on the degree of anger among quitting addicts. There were no significant differences between the mean scores of anger before the intervention in both intervention and control groups, but after the intervention, the mean scores of anger in the group receiving LST had a significant difference. In fact, due to the implementation of LST program, the rate of anger and aggressive behaviour significantly reduced among the quitting addicts.

In line with these results, in a study that examined the effect of cognitive-behavioural group therapy on the aggression of addicted people referred to addiction treatment clinics, the effectiveness of cognitive-behavioural group therapy was shown in the reduction of verbal and physical aggression, anger and hostility. ${ }^{[29]}$

The findings of another study on the effect of stress management training on the quality of life of addicts under methadone maintenance treatment showed that, the scores of quality of life of the intervention group was significantly higher, suggesting that the stress management program is effective in increasing the quality of life of addicts under maintenance treatment with methadone.[16]

Furthermore, other results about the effect of emotional regulation training for the purpose of anger reduction and the goal of teaching excitement training in drug addicts showed that addicts face more problems in regulating their emotions, and also the training on emotional regulation, and how to express it and manage emotions can help to control anger, thus reduces emotional problems.[13] Regarding the effect of LST on control of anger and anxiety in students, the results of a study indicated that LST reduced anxiety and aggression and improved psychological status.[30]

It is worth noting that, so far, no studies have been conducted specifically on the use of LST on controlling the anger of quitting drug addicts. However, in this regard, the findings of a study conducted to investigate the effect of LST on the people quitting drug indicated that, this program could reduce the anxiety and depression of addicted people who are trying to quit. [20] Additionally, findings of another study on the effect of LST indicated that, this training not only provided effective techniques to counteract stress and emotions, but also improved the quality of life of individuals.[21] Moreover, findings of a longitudinal study indicated that, LST is effective in improving social skills, selfmanagement, and drug resistance, and reduces the risk of substance abuse.[2,28]

Results of the present study and the review of the literature suggested that paying attention to impulse and control of anger helps people who are quitting drugs to use more effective coping strategy, as well as regulating emotions and reducing aggressive behaviours in life. Additionally, one of the skills taught in our sessions by which one could control anger, was the problem-solving skill, which is an important part of everyday life for each person. Problem solving skills provide conditions for implementing an adaptive response to social situations, enabling individuals to look at the subject from a different angle and choose the appropriate solution. [31]

Involvement of addicts attending the psychiatric center in Zahedan through LST is important because it had a significant effect on their aggression. Thus, it is recommended that, this type of training, which involves the addicts, should also be used for other Iranian addiction rehab centers.

Among the limitations of this study was the difficult follow-up of patients after discharge due to family concerns about drug re-use, to the extent that, they changed their previous phone numbers (To prevent contact to previous addicted friends) and this led to difficulty accessing them, and this was one of the reasons for the drop of the sample.

\section{CONCLUSIONS}

The findings of this study showed that LST can reduce the anger and aggressive behaviours of these individuals. Thus, considering the high co-morbidity of this disorder with the use of drugs, and since this factor can be considered as a barrier to the treatment of drug abuse, it is suggested that, it should be considered in the treatment process. It is suggested that, LST should be used in the drug rehabilitation centers to prevent people from resuming drug use, along with detoxification treatments. Training life skills show the addicts 
how to regulate emotions, which consequently results in anger control and reduced aggression.

\section{ACKNOWLEDGEMENT}

The authors thank all the participants of this study and also the nurses of the Zahedan Psychiatric Hospital who accompanied us during this research. This article is a part of the master's thesis at Zahedan University of Medical Sciences.

\section{REFERENCES}

[1] Naquiah FMZ, James RJ, Suratman S, et al. Transgenerational effects of paternal heroin addiction on anxiety and aggression behavior in male offspring. Behav Brain Funct 2016;12(1):23.

[2] Velasco V, Griffin KW, Botvin GJ. Preventing adolescent substance use through an evidence-based program: effects of the Italian adaptation of life skills training. Prev Sci 2017;18(4):394-405.

[3] Moshki M, Hassanzade T, Taymoori P. Effect of life skills training on drug abuse preventive behaviors among university students. International Journal of Preventive Medicine 2014;5(5):577-83.

[4] Sajjadi SS, Sajjadi SH. A study on prevalence of drug usage among teenagers in the Lamerd and Mohr cities. Asian Journal of Medical and Pharmaceutical Researches 2012;2(1):1-4.

[5] Fooladvand K, Borjali A, Sabet HF, et al. Decision-making styles and attitude towards substances: predictors of potential addiction in adolescents. Journal of Practice in Clinical Psychology 2017;5(2):91-8.

[6] Saatcioglu 0, Erim R. Aggression among male alcoholdependent inpatients who smoke cigarettes. J Psychol 2009;143(6):615-24.

[7] Murray CE, Mobley AK. Empirical research about samesex intimate partner violence: a methodological review. J Homosex 2009;56(3):361-86.

[8] Afkari ME, Ghasemi A, Shojaeizadeh D, et al. Comparison between family function dimensions and quality of life among amphetamine addicts and non-addicts. Iran Red Crescent Med Journal 2013;15(4):356-62.

[9] Massah O, Sohrabi F, A'azami Y, et al. Effectiveness of gross model-based emotion regulation strategies training on anger reduction in drug dependent individuals and its sustainability in follow-up. Int J High Risk Behav Addict 2016;5(1):e24327.

[10] Matuszka B, Bacskai E, Czobor P, et al. Physical aggression and concurrent alcohol and tobacco use among adolescents. International Journal of Mental Health and Addiction 2017;15(1):90-9.

[11] Doran N, McChargue D, Cohen L. Impulsivity and the reinforcing value of cigarette smoking. Addict Behav 2007;32(1):90-8.

[12] Hill CE, Kanazawa Y, Knox S, et al. Meaning in life in psychotherapy: the perspective of experienced psychotherapists. Psychother Res 2017;27(4):381-96.

[13] Choopan H, Kalantarkousheh SM, Aazami Y, et al. Effectiveness of emotion regulation training on the reduction of craving in drug abusers. Addict Health 2016;8(2):68-75.

[14] Khaledian M, Yarahmadi M, Mahmoudfakhe H. Effect of group logotherapy in reducing depression and increasing hope in drug addicts. Journal of Research \& Health 2016;6(1):167-74.

[15] Hojjat SK, Raufpoor R, Khalili MN, et al. Effects of vocational consultation on relapse rate and hope among drug dependents in Bojnurd, Iran. Electron Physician 2016;8(1):1711-7.

[16] Zarei S, Asadi Z, Zarei KH. The Effectiveness of stress management program on quality of life among metadon maintenance treatment members. Quarterly Journal of Research on Addiction 2014;8(29):9-19.

[17] Gousheh A, Ziaaddini H, Baneshi MR, et al. Drug use among residents of juvenile correctional center in Kerman, Iran, and its relationship with personality dimensions and self-concept. Addict Health Journal 2014;6(1-2):22-9.

[18] Dimeff LA, Linehan MM. Dialectical behavior therapy for substance abusers. Addict Sci Clin Pract 2008;4(2):3947.

[19] Navidian A, Kermansaravi F, Tabas EE, et al. Efficacy of group motivational interviewing in the degree of drug craving in the addicts under the Methadone Maintenance Treatment (MMT) in South East of Iran. Arch Psychiatr Nurs 2016;30(2):144-9.

[20] Habibi Z, Tourani S, Sadeghi H, et al. Effectiveness of stress management skill training on the depression, anxiety and stress levels in drug addicts after drug withdrawal. Int J High Risk Behav Addict 2013;2(2):82-6.

[21] Esmatpanah O, Khakshor $H$. The effectiveness of life skills training on tendency toward opium in clients who referred to rehabilitation and treatment centers of addiction. Quarterly Journal of Research on Addiction 2010;3(12):41-52.

[22] Hojjat SK, Rezaei M, Namadian G, et al. Effectiveness of emotional intelligence group training on anger in adolescents with substance-abusing fathers. Journal of Child \& Adolescent Substance Abuse 2017;26(1):24-9.

[23] Lashkaripour K, Bakhshani NM, Sadjadi SA. Quality of life in patients on methadone maintenance treatment: a three-month assessment. J Pak Med Assoc 2012;62(10):1003-7.

[24] Naseri A, Babakhani N. The effect of life skills training on physical and verbal aggression male delinquent adolescents marginalized in Karaj. Social and Behavioral Sciences 2014;116:4875-9.

[25] Sayar S, Eghlima M. A comparison of family functionality in addicted and non-addicted married men. Journal of Paramedical Science and Rehabilitation (JPSR) 2014;2(2):35-41.

[26] Mohammadi N. A preliminary study of the psychometric properties of Buss and Perry's aggression questionnaire. Journal of Social Sciences and Humanities of Shiraz University 2007;25(4):135-51.

[27] Reyna C, Lello IMG, Sanchez A, et al. The Buss-Perry aggression questionnaire: construct validity and gender invariance among argentinean adolescents. International Journal of Psychological Research 2011;4(2):30-7. 
[28] Rezaee N, Navidian A, Moshtaghi E. The effectiveness of life skills training on the level of hope in recovering addicts referring to the Zahedan Psychiatric Center. Sadra Med Sci 2017;5(4):187-98.

[29] Hofmann SG, Asnaani A, Vonk IJ, et al. The efficacy of cognitive behavioral therapy: a review of meta-analyses. Cognit Ther Res 2012;36(5):427-40.
[30] Thomas RE, McLellan J, Perera R. Effectiveness of schoolbased smoking prevention curricula: systematic review and meta-analysis. BMJ Open 2015;5(3):e006976.

[31] Mofrad SHK, Mehrabi T. The role of self-efficacy and assertiveness in aggression among high-school students in Isfahan. J Med Life 2015;8(Spec 4):225-31. 